\title{
PENGARUH TINGKAT PEMENUHAN KEBUTUHAN FISIK DAN AKTUALISASI DIRI PADA KELOMPOK PENDAPATAN TERHADAP PERSEPSI HAND PHONE MEREK CHINA
}

\author{
Taryana
}

\author{
taryana.suaib@gmail.com
}

\begin{abstract}
Abstrak
Penelitian ini dilatarbelakangi adanya berbagai macam kebutuhan manusia yang harus dipenuhi secara bertahap pada kelompok pendapatan tertentu sebagaimana teori yang disampaikan Maslow. Adapun yang menjadi permasalahan dalam penelitian ini adalah pada kelompok pendapatan kurang dari lima juta rupiah apakah faktor tingkat terpenuhinya hierarki kebutuhan fisik dan kebutuhan aktualisasi diri berpengaruh terhadap persepsi hand phone merek china dan pada kelompok pendapatan lebih dari sama dengan lima juta rupiah apakah faktor tingkat terpenuhinya hierarki kebutuhan fisik dan kebutuhan aktualisasi diri berpengaruh terhadap persepsi hand phone merek china. Populasi dalam penelitian ini adalah pekerja dan berstatus mahasiswa dilingkungan Universitas Muhammadiyah Tangerang Banten. Dengan pendekatan kuantitatif penelitian ini bertujuan untuk mengetahui seberapa besar pengaruh tingkat pemenuhan kebutuhan fisik dan tingkat pemenuhan kebutuhan aktualisasi diri terhadap persepsi hand phone merek china pada dua kelompok pedapatan tersebut. Teknik analisis data dengan regresi linear yang berfungsi untuk membuktikan hipotesis penelitian. Dari hasil analisis data diperoleh bahwa faktor tingkat terpenuhinya hierarki kebutuhan fisik dan tingkat terpenuhinya kebutuhan aktualisasi diri pada kedua kelompok pedapatan tersebut tidak berpengaruh signifikan terhadap persepsi hand phone merek china. Pengujian hipotesis menggunakan uji $\mathrm{t}$ dan uji $\mathrm{F}$ menunjukkan bahwa kedua variabel independen yang diteliti terbukti tidak signifikan mempengaruhi variabel dependen. Angka Adjusted $R$ square sebesar 0,023 atau 2,3\% pada kelompok pendapatan kurang dari lima juta rupiah dan 0,004 atau 0,44\% pada kelompok pendapatan lebih dari lima juta rupiah menunjukkan bahwa variasi persepsi hand phone merek china bisa dijelaskan oleh kedua variabel independen tersebut.
\end{abstract}

Kata kunci: Kebutuhan fisik, Kebutuha aktualisasi diri dan Persepsi merek. 


\begin{abstract}
This research is based on the existence of various kinds of human needs that must be met gradually in certain income groups as the theory presented by Maslow. As for the problem in this research is in the group of income less than five million rupiah whether the level factor of fulfillment of hierarchy of physical needs and requirement of self actualization influence to perception of hand phone chinese brand and income group more than equal to five million rupiah whether factor hierarchy level fulfillment physical needs and self actualization needs affect the perception of hand phone chinese brand. Population in this research is worker and student status in Muhammadiyah University Tangerang Banten. With quantitative approach of this study aims to find out how much influence the level of physical needs fulfillment and the level of self actualization needs fulfillment to the perception of hand phone chinese brand in two groups income. Data analysis techniques with linear regression that serves to prove the research hypothesis. From result of data analysis, it is found that hierarchy level of physical requirement hierarchy and the level of fulfillment of self actualization requirement in both income group has no significant effect to perception of hand phone chinese brand. Hypothesis testing using t test and $\mathrm{F}$ test showed that the two independent variables studied proved not significantly affect the dependent variable. The Adjusted R square number of 0,023 or 2,3\% in the income group of less than five million rupiah and 0,004 or $0,44 \%$ in the income group more than five million rupiah indicates that the variation of the perception of hand phone chinese brand can be explained by the two independent variables.
\end{abstract}

Keywords: Physical needs, Self actualization and brand perception 
Pendahuluan

Latar belakang

Pada dasarnya manusia terlahir didunia akan selalu membutuhkan apa saja yang sesuai dengan keperluan saat itu. Pada saat bayi lahir membutuhkan minum dari air susu ibunya, membutuhkan kain atau pakaian agar tidak kedinginan dan berfungsi sebagai pelindung dan membutuhkan juga kasih sayang dari orang tuanya. Seiring dengan pertumbuhan fisik bayi tersebut berubah pula kebutuhan-kebutuhanya misalkan saja membutuhkan susu formula, membutuhkan imunisasi, membutuhkan vitamin, membutuhkan bubur, sayur, lauk buahbuahan dan lain sebagainya, sehingga secara umum dapat dikatakan bahwa seiring dengan pertumbuhan atau kedewasaan seorang manusia akan diiringi dengan perubahan kebutuhan-kebutuhanya baik kebutuhan fisik maupun non fisik.

Adanya kebutuhan fisik, kebutuhan rasa aman, kebutuhan sosial, kebutuhan ego dan kebutuhan aktualisasi diri sebagaimana disampaikan oleh Maslow tentunya ada faktor pendorong yang biasa kita kenal dengan istilah motivasi, sementara motivasi sendiri timbul atau muncul karena adanya perbedaan antara apa yang seharusnya dirasakan dengan kenyataan yang dirasakan. Dalam memenuhi kebutuhan-kebutuhan tersebut tentunya masing-masing individu akan berbeda-beda pilihanya sehingga persepsi preferensi terhadap sebuah merek tentu juga akan berbeda. Terkait latar belakang ini penulis tertarik untuk mengetahui dan mengungkapkan "Korelasi Teori Heararki Kebutuhan Maslow Dengan Persepsi Preferensi Merek-Merek China"

Rumusan Masalah
Berdasarkan latar belakang masalah tersebut di atas, penulis merumuskan sebagai berikut:

a. Seberapa besar pengaruh tingkat terpenuhinya hierarki kebutuhan fisik pada kelompok pendapatan tertentu terhadap persepsi hand phone merek china?

b. Seberapa besar pengaruh tigkat terpenuhiya hierarki kebutuhan aktualisasi diri pada kelompok pendapatan tertentu terhadap persepsi hand phone merek china?

c. Seberapa besar pengaruh tingkat terpenuhinya hierarki kebutuhan fisik dan kebutuhan aktualisasi diri pada kelompok pendapatan tertetu secara simultan terhadap persepsi hand phone merek china?

\section{Maksud dan Tujuan}

Berdasarkan rumusan masalah tersebut di atas, penelitian ini bertujuan antara lain sebagai berikut:

a. Mengetahui besarnya pengaruh hubungan antara hierarki kebutuhan fisik pada kelompok pendapatan tertentu terhadap persepsi hand phone merek china?

b. Mengetahui besarnya pengaruh hubungan antara hierarki kebutuhan aktualisasi diri pada kelompok pendapatan tertentu terhadap persepsi hand phone merek china?

c. Mengetahui besarnya pengaruh hubungan antara hierarki kebutuhan fisik dan kebutuhan aktualisasi diri pada kelompok pendapatan tertentu secara simultan terhadap persepsi hand phone merek china? 
Model Motivasi

Kajian Pustaka

Motivasi

Motivasi merupakan suatu faktor pendorong seseorang untuk melakukan suatu tindakan tertentu, sehingga motivasi sering juga dikatakan sebagai pendorong perilaku seseorang. Terkait dengan motivasi ada beberapa pendapat para ahli antara lain menurut Miftah (2012:203) motivasi merupakan salah satu unsur pokok dalam perilaku seseorang dan motivasi merupakan suatu proses psikologi. Menurut Badrudin (2014:191) motivasi adalah kondisi psikologis dalam diri individu yang menggerakkan individu untuk bertindak sehingga terjadi perubahan tingkah laku yang disadari untuk mencapai tujuan. Sedangkan menurut Indra (2009:117) motivasi didefinisikan sebagai semua upaya untuk memunculkan dari dalam semangat orang lain (bawahan) agar mau bekerja keras guna mencapai tujuan organisasi melalui pemberian atau penyediaan pemuasan kebutuhan mereka. Menurut Suparno (2015:186) motivasi adalah kekuatan yang ada dalam seseorang, yang mendorong perilakunya untuk melakukan tindakan. Hal serupa yang disampaikan Kadarisman (2013:278) motivasi diartikan penggerak atau pendorong dalam diri seseorang untuk mau berperilaku dan bekerja dengan giat dan baik sesuai dengan tugas dan kewajiban yang telah diberikan kepadanya.

Schiffman dan Kanuk dalam Balqiah dan Setyowardhani 2010 mendefinisikan motivasi sebagai tenaga dorong dalam diri individu yang memaksa mereka untuk bertindak. Tenaga dorong tersebut dihasilkan oleh keadaan tertekan, yang timbul sebagai akibat kebutuhan yang tidak terpenuhi.

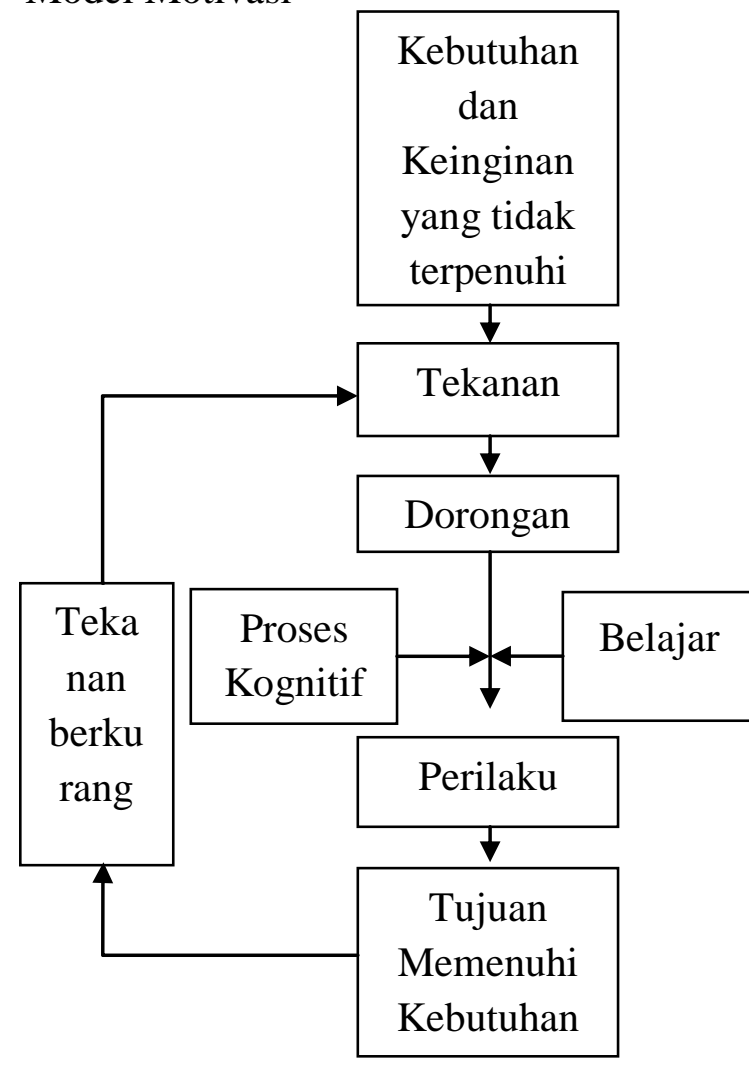

Gambar Model Motivasi

Sumber: Schiffman dan Kanuk 2000, dalam Balqiah dan Setyowardhani

Dari gambar tersebut diatas menjelaskan bagaimana motivasi terbentuk, yang diawali dengan adanya rangsangan yang akan menyebabkan pengenalan kebutuhan. Sebagai contoh adanya gap yang timbul sebagai akibat adanya rasa lapar dan haus sehingga konsumen merasa adanya pengenalan kebutuhan akan makanan dan minuman. Pengenalan kebutuhan akan menyebabkan tekanan (tension) kepada konsumen sehingga ada dorongan pada dirinya (drave state) untuk melakukan tindakan yang bertujuan (goal-directed behavior). Dan tindakan tersebut bisa bermacam-macam, antara lain konsumen akan mencari informasi mengenai produk, merek atau toko, konsumen mungkin akan membicarakan dengan teman, kerabat, atau 
mungkin konsumen akan membeli produk atau jasa tersebut untuk memenuhi kebutuhan.

\section{Hierarki Kebutuhan Maslow}

Teori Maslow (Maslow's hierarchy of needs) mengemukakan lima kebutuhan manusia berdasarkan tingkat kepentinganya dari yang paling rendah atau mendasar sampai dengan yang paling tinggi. Konsumen yang kebutuhan dasarnya telah terpenuhi maka kebutuhan lainya lebih tinggi biasanya akan muncul dan seterusnya. Adapun hierarki kebutuhan Maslow sebagai berikut:

Kebutuhan fisiologis, kebutuhan ini merupakan kebutuhan dasar manusia, yaitu kebutuhan tubuh manusia agar tetap hidup, yang meliputi kebutuhan makan, minum, pakaian, tempat tinggal, udara.

Kebutuhan rasa aman, kebutuhan ini merupakan cerminan kebutuhan perlindungan dari fisik manusia, karena manusia membutuhkan rasa aman dari berbagai gangguan seperti kriminalitas, bencana alam dan lain-lain sehingga manusia merasa aman dan nyaman ketika berada dirumah maupun pada saat bepergian.

Kebutuhan sosial, tingkat kebutuhan ketiga dalam teori ini manusia membutuhkan rasa kasih sayang dari orang lain, rasa memiliki dan dimiliki serta dapat diterima dalam lingkungan masyarakat, manusia perlu saling berhubungan.

Kebutuhan ego, dalam teori ini ego atau esteem yang merupakan tingkat keempat, merupakan kebutuhan untuk berprestasi sehingga dapat mencapai derajat yang lebih tinggi dari yang lainya, atau mencapai karir yang melebihi dari yang lainya.
Kebutuhan aktualisasi diri, yakni keinginan manusia untuk menjadikan dirinya sebagai orang yang terbaik sesuai dengan potensi dan kemampuan yang dimilikinya. Manusia butuh mengekpresikan dirinya kedalam suatu aktifitas untuk membuktikan dirinya bahwa ia bisa melakukan hal tersebut.

\section{Persepsi}

Balqiah \& Setyowardhani 2010, mendefinisikan persepsi sebagai proses yang dilakukan individu untuk memilih, mengatur, dan menafsirkan stimuli ke dalam gambar yang berarti dan masuk akal mengenai dunia. Toha 2012 persepsi pada hakikatnya adalah proses kognitif yang dialami oleh setiap orang di dalam memahami informasi tentang lingkungannya, baik lewat penglihatan, pendengaran, penghayatan perasaan, dan penciuman.

Persepsi dapat ditimbulkan oleh faktor internal dan eksternal, faktor internal ini dapat ditimbulkan atas proses pemahaman sesuatu yang termasuk didalamnya sistem nilai tujuan, kepercayaan dan tanggapanya terhadap hasil yang dicapai, sementara faktor eksternal yang berupa lingkungan, sedangkan menurut Kotler dan Keller (2016:228), persepsi tidak hanya bergantung pada rangsangan fisik tapi juga rangsangan yang berhubungan dengan lingkungan sekitar dan keadaan individu yang bersangkutan.

\section{Ekuitas Merek}

Sikap merek (brand attitude) merupakan aspek penting dari ekuitas merek karena ekuitas merek menyangkut nilai suatu merek bagi pemasar maupun konsumen. Dari sudut 
pandang konsumen ekuitas merek melibatkan suatu sikap merek positif yang kuat, evaluasi yang baik terhadap suatu merek yang didasarkan pada kepercayaan dan arti baik yang dapat diakses dari dalam ingatan.

\section{PEMBAHASAN}

Dalam penelitian ini pengambilan sampel dengan metode simple random sampling, yakni teknik pengambilan sampel dari populasi yang dilakukan secara acak tanpa memperhatikan strata yang ada dalam populasi ini untuk dijadikan sampel

Data responden berdasarkan pendapatan:

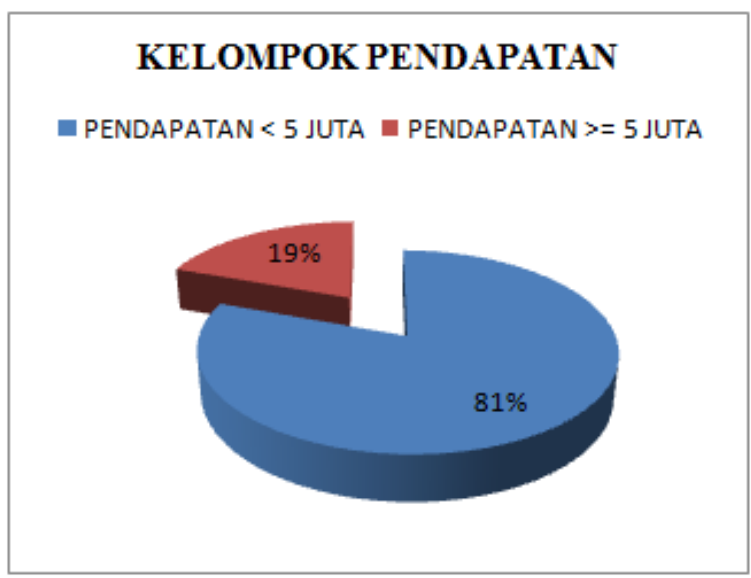

Sumber : data diolah 2018

Data responden berdasarkan tingkat pemenuhan kebutuhan sesuai hierarki Maslow:

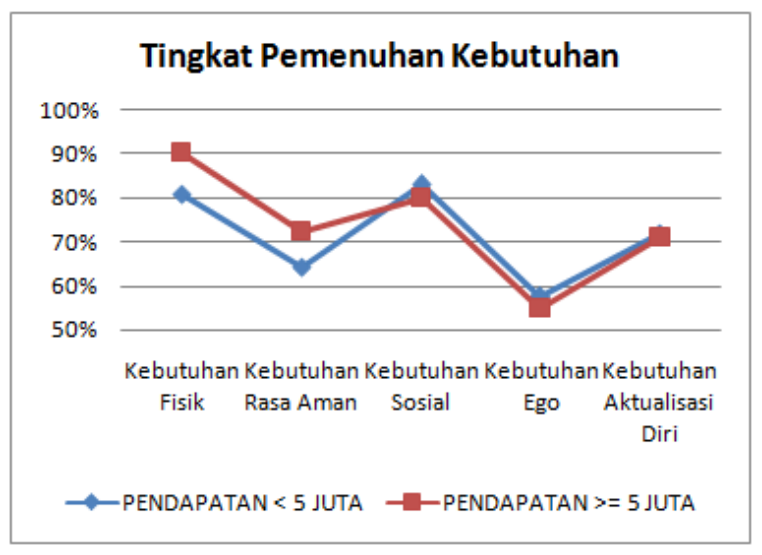

Data responden berdasarkan tingkat persepsi terhadap hand phone merek china

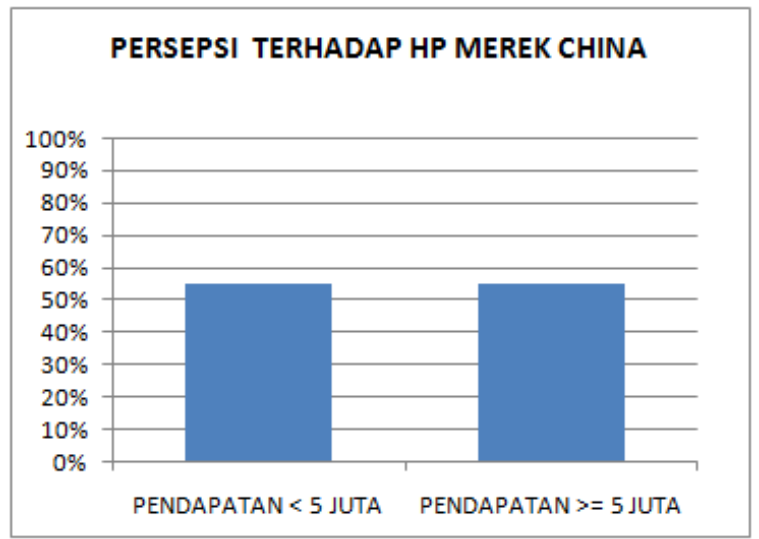

Analisis Regresi Tingkat Pendapatan Kurang Dari Lima Juta Rupiah

\begin{tabular}{|c|c|c|c|c|}
\hline \multicolumn{5}{|c|}{ Model Summary } \\
\hline Model & $\mathrm{R}$ & $\begin{array}{c}\mathrm{R} \\
\text { Square }\end{array}$ & $\begin{array}{c}\text { Adjusted } \\
\text { R } \\
\text { Square }\end{array}$ & $\begin{array}{c}\text { Std. } \\
\text { Error of } \\
\text { the } \\
\text { Estimate }\end{array}$ \\
\hline 1 & $.216^{\mathrm{a}}$ & .047 & .023 & 4.279 \\
\hline
\end{tabular}

Nilai Adjusted R Square sebesar 0,023 atau sebesar 2,29\% menujukkan pengaruh yang kecil dari variabel kebutuhan aktualiasi diri dan kebutuhan fisik terhadap persepsi merek. 
ANOVA $^{\mathrm{a}}$

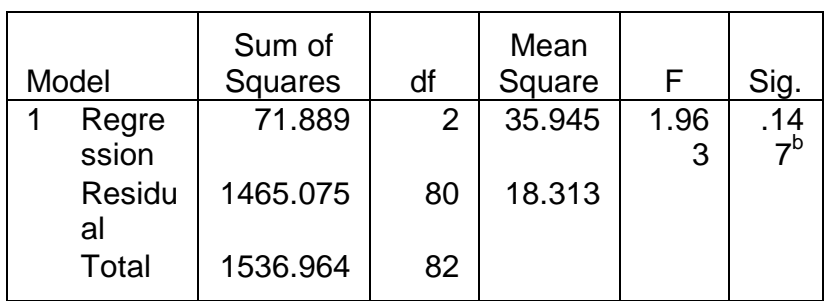

a. Dependent Variable: Persepsi Merek

b. Predictors: (Constant), Kebutuhan Aktualisasi Diri, Kebutuhan Fisik

Nilai signifikansi 0,147 pada tabel Anova tersebut di atas yang nilai tersebut lebih besar dari 0,05 menunjukkan bahwa variabel kebutuhan aktualisasi diri dan kebutuhan fisik tidak berpengaruh terhadap persepsi merek.

\begin{tabular}{|c|c|c|c|c|c|}
\hline \multicolumn{6}{|c|}{ Coefficients $^{a}$} \\
\hline \multirow[b]{2}{*}{ Model } & \multicolumn{2}{|c|}{$\begin{array}{c}\text { Unstandardiz } \\
\text { ed } \\
\text { Coefficients }\end{array}$} & \multirow{2}{*}{$\begin{array}{c}\text { Stand } \\
\text { ar } \\
\text { dized } \\
\text { Coeff } \\
\text { icient } \\
\text { s } \\
\text { Beta }\end{array}$} & \multirow[b]{2}{*}{$\mathrm{T}$} & \multirow[b]{2}{*}{ Sig. } \\
\hline & B & $\begin{array}{l}\text { Std. } \\
\text { Error }\end{array}$ & & & \\
\hline $1 \quad$ (Constant) & 8.045 & $\begin{array}{r}3.12 \\
7\end{array}$ & & $\begin{array}{r}2.57 \\
3\end{array}$ & .012 \\
\hline $\begin{array}{l}\text { Kebutuhan } \\
\text { Fisik }\end{array}$ & .162 & .138 & .130 & $\begin{array}{r}1.17 \\
6\end{array}$ & .243 \\
\hline $\begin{array}{l}\text { Kebutuhan } \\
\text { Aktualisasi } \\
\text { Diri }\end{array}$ & .140 & .099 & .156 & $\begin{array}{r}1.41 \\
9\end{array}$ & .160 \\
\hline
\end{tabular}

a. Dependent Variable: Persepsi Merek

Nilai coefficients kebutuhan fisik sebesar 0,243 dan nilai coefficients kebutuhan aktualisasi diri sebesar 0,160 dimana nilainilai tersebut lebih besar dari 0,05 sehingga masing-masing variabel tersebut tidak begitu berpengaruh terhadap persepsi merek.
Analisis Regresi Tingkat Pendapatan Lebih Dari Sama Dengan Lima Juta Rupiah

\begin{tabular}{l|l|r|r|r|}
\hline & & & Model Summary \\
\hline Model & $\mathrm{R}$ & $\mathrm{R}$ & $\begin{array}{c}\text { Adjusted } \\
\mathrm{R} \\
\text { Square } \\
\text { Square }\end{array}$ & $\begin{array}{c}\text { Error of } \\
\text { the } \\
\text { Estimate }\end{array}$ \\
\hline 1 & $.330^{\mathrm{a}}$ & .109 & .004 & 2.969 \\
\hline
\end{tabular}
a. Predictors: (Constant), Kebutuhan Aktualisasi
Diri, Kebutuhan Fisik

Nilai Adjusted R Square sebesar 0,004 atau sebesar 0,44\% menujukkan pengaruh yang sangat kecil dari variabel kebutuhan aktualiasi diri dan kebutuhan fisik terhadap persepsi merek.

ANOVA $^{\mathrm{a}}$

\begin{tabular}{|c|c|c|c|c|c|}
\hline Model & $\begin{array}{c}\text { Sum of } \\
\text { Square } \\
\text { s }\end{array}$ & $\mathrm{df}$ & $\begin{array}{c}\text { Mean } \\
\text { Squar } \\
\text { e }\end{array}$ & $F$ & Sig. \\
\hline $\begin{array}{l}1 \text { Regressi } \\
\text { on }\end{array}$ & 18.361 & 2 & 9.180 & $\begin{array}{r}1.04 \\
2\end{array}$ & .374 \\
\hline Residual & $\begin{array}{r}149.83 \\
9\end{array}$ & 17 & 8.814 & & \\
\hline Total & $\begin{array}{r}168.20 \\
0\end{array}$ & 19 & & & \\
\hline
\end{tabular}

a. Dependent Variable: Persepsi Merek

b. Predictors: (Constant), Kebutuhan Aktualisasi Diri, Kebutuhan Fisik

Nilai signifikansi 0,374 pada tabel Anova tersebut di atas yang nilai tersebut lebih besar dari 0,05 menunjukkan bahwa variabel kebutuhan aktualisasi diri dan kebutuhan fisik tidak berpengaruh terhadap persepsi merek. 


\section{Coefficients $^{\mathrm{a}}$}

\begin{tabular}{|c|c|c|c|c|c|}
\hline \multirow[b]{2}{*}{ Model } & \multicolumn{2}{|c|}{$\begin{array}{l}\text { Unstandardi } \\
\text { zed } \\
\text { Coefficients }\end{array}$} & $\begin{array}{l}\text { Standardi } \\
\text { zed } \\
\text { Coefficien } \\
\text { ts }\end{array}$ & & \\
\hline & B & $\begin{array}{c}\text { Std. } \\
\text { Erro } \\
r\end{array}$ & Beta & $t$ & Sig \\
\hline $\begin{array}{ll}1 & \text { (Consta } \\
\text { nt) }\end{array}$ & $\begin{array}{r}10.2 \\
40\end{array}$ & $\begin{array}{r}7.76 \\
3\end{array}$ & & $\begin{array}{r}1.3 \\
19\end{array}$ & $\begin{array}{r}.20 \\
5\end{array}$ \\
\hline $\begin{array}{l}\text { Kebutu } \\
\text { han } \\
\text { Fisik }\end{array}$ & .335 & .349 & .227 & $\begin{array}{r}.95 \\
9\end{array}$ & $\begin{array}{r}.35 \\
1\end{array}$ \\
\hline $\begin{array}{l}\text { Kebutu } \\
\text { han } \\
\text { Aktualis } \\
\text { asi Diri }\end{array}$ & -.231 & .180 & -.303 & $\begin{array}{r}- \\
1.2 \\
81\end{array}$ & $\begin{array}{r}.21 \\
7\end{array}$ \\
\hline
\end{tabular}

a. Dependent Variable: Persepsi Merek

Pada tingkat pendapatan lebih dari sama dengan lima juta rupiah dengan tingkat pemenuhan kebutuhan fisik sebesar 90\% dan tingkat pemenuhan kebutuhan aktualisasi diri sebesar $71 \%$ dengan nilai adjusted R square sebesar 0,004 atau sebesar $0,44 \%$ menujukkan pengaruh yang sangat kecil dari variabel kebutuhan fisik dan kebutuhan aktualiasi diri terhadap persepsi hand phone merek china.

Semakin tinggi pendapatan dan semakin terpenuhinya kebutuhan fisik dan kebutuhan aktualisasi diri maka persepsi terhadap hand phone merek china semakin rendah

\section{DAFTAR PUSTAKA}

0,351 dan nilai coefficients kebutuhan aktualisasi diri sebesar 0,217 dimana nilainilai tersebut lebih besar dari 0,05 sehingga masing-masing variabel tersebut sangat tidak berpengaruh terhadap persepsi merek.

\section{Kesimpulan}

Dari pembahasan tersebut di atas dapat disimpulkan bahwa:

Pada tingkat pendapatan kurang dari lima juta rupiah dengan tingkat pemenuhan kebutuhan fisik sebesar $81 \%$ dan tingkat pemenuhan kebutuhan aktualisasi diri sebesar $72 \%$ dengan nilai adjusted $\mathrm{R}$ square sebesar 0,023 atau sebesar 2,29\% menujukkan pengaruh yang kecil dari variabel kebutuhan fisik dan kebutuhan aktualiasi diri terhadap persepsi hand phone merek china.

Badrudin. 2014. Dasar-Dasar Manajemen, Cetakan Kedua, Alfa Beta Bandung

Iman, Indra dan Siswandi. 2009. Aplikasi Manajemen Perusahaan, Analisis Kasus dan Pemecahanya. Edisi ke-2. Jakarta. Mitra Wacana Media.

Kadarisman. 2013. Manajemen Pengembangan Sumber Daya Manusia. Cetakan Ke-2. Raja Grafindo Perkasa. Jakarta

Miftah, Thoha. 2012. Perilaku Organisasi, Edisi 1,22, Rajawali Pers, Jakarta

Sugiyono. 2012. Metode Penelitian Bisnis. Cetakan ke-16. Alfabeta. Bandung. ----------- 2011. Metode Penelitian Administrasi. Cetakan ke-19. Alfabeta. Bandung. 
Suparno, Widodo, E. 2015. Manajemen Pengembangan Sumber Daya Manusia, Cetakan ke-1, Pustaka Pelajar, Yogyakarta

Peter, Paul dan Olson, Jerry, 2003. Consumer Behavior, Perilaku Konsumen dan Strategi Pemasaran

Xiao Tong, Jana Hawley,2009. Measuring Customer Based Brand Equity, Empirical Evidence from the Sportswear Market in China. Journal of Product \& Brand Management, Vol. 18 